\title{
Chile 2016: ¿EL NADIR DE LA LeGITIMIDAd DEMOCRÁTICA?*
}

\author{
Chile 2016: The nadir of democratic legitimacy?
}

\author{
IGNACIO ARANA ARAYA \\ Pontificia Universidad Católica de Chile
}

\section{RESUMEN}

Este artículo argumenta que la legitimidad del sistema político se encuentra en su punto más bajo desde el retorno a la democracia. El 2016 fue el año en el que un presidente recibió la mayor desaprobación, el que registró el mayor ausentismo electoral, el que padeció la mayor desconfianza en los tres poderes del Estado, y el que registró la menor identificación con partidos políticos. La baja legitimidad política del sistema puede relacionarse a causas coyunturales - mala gestión gubernamental y escándalos de corrupción-y subyacentes —desconfianza interpersonal, desapego de la actividad política y élites cerradas- que explican la baja legitimidad. De continuar esta tendencia, esta etapa de baja legitimidad puede transformar el sistema de partidos, favorecer el surgimiento de movimientos y liderazgos populistas, y erosionar la calidad de la democracia chilena.

Palabras clave: Chile, deslegitimización, élites, desconfianza, Bachelet

\begin{abstract}
This article argues that the legitimacy of the political system is currently at its lowest point since the return to democracy. Presidential approval ratings dipped to a record low in 2016. The year also saw the highest levels of electoral absenteeism and distrust in the three branches of government, and the lowest levels of identification with political parties. This low legitimacy of the political system can be attributed to cyclical - governmental mismanagement and corruption scandals - and underlying causes -interpersonal mistrust, detachment from the political activity and insulated elites-. If these trends continue, we may witness a transformation of the party system, the emergence of populist movements and leaders, and the erosion of the quality of Chilean democracy.
\end{abstract}

Key words: Chile, delegitimization, elites, mistrust, Bachelet

El autor agradece al proyecto FONDECYT N³160357 por su generoso financiamiento para elaborar este manuscrito. 


\section{INTRODUCCIÓN}

Tomando como referencia el retorno a la democracia en 1990, la legitimidad del sistema político chileno registró una serie de récords negativos en 2016. La Presidenta Michelle Bachelet se consolidó como la jefe de gobierno más impopular (15\% de apoyo), y se llegó al punto más bajo en participación electoral (34,9\% de votantes en las elecciones municipales de octubre), en la confianza en los tres poderes del Estado y en la identificación ciudadana con partidos políticos. Asimismo, las encuestas revelaron un pesimismo general sobre el rumbo que sigue el país.

En este artículo se sugiere que existen causas coyunturales y subyacentes que explican la caída en la legitimidad del sistema político. Entre las causas coyunturales se encuentran problemas de gestión por parte del gobierno (particularmente por la marcha de las reformas), y la pérdida de confianza en las élites políticas y económicas por los escándalos de corrupción. Ambos factores ya estaban presentes en 2015 (ver Gamboa y Segovia 2016), pero su extensión en 2016 profundizó la caída de la legitimidad. Entre los factores subyacentes se encuentran una baja confianza interpersonal, un desapego de la actividad política, y la baja circulación de las élites.

En la siguiente sección se analizan los principales acontecimientos que marcaron las coyunturas política, social, económica e internacional. La tercera sección examina los cambios ocurridos en instituciones y políticas públicas. La cuarta repasa las elecciones municipales, mientras que la quinta revisa los principales hechos ocurridos en los poderes Ejecutivo y Legislativo, y la relación entre ambos. La quinta parte examina las potenciales consecuencias de la deslegitimación del sistema político. Se argumenta que, de pronunciarse, esta etapa de deslegitimidad puede transformar el sistema de partidos, favorecer el surgimiento de movimientos y liderazgos populistas, y erosionar la calidad de la democracia chilena. En la conclusión se discuten potenciales escenarios para 2017, año que debido a las elecciones legislativas y presidenciales reconfigurará las fuerzas políticas para el siguiente cuatrienio.

\section{TEMAS SOBRESALIENTES EN LA AGENDA NACIONAL}

\section{Coyuntura política y social}

La presidenta Bachelet se transformó a mediados de 2016 en la mandataria con menor aprobación desde 1990, según la encuesta del Centro de Estudios Públicos (CEP 2017). ${ }^{1}$ Bachelet registró una aprobación de $15 \%$ y una desaprobación de $66 \%$

La encuesta CEP se usa como referente por ser la más prestigiosa pero otras encuestadoras como CADEM y Adimark mostraron un nivel similar de desaprobación: http://www.cnnchile.com/noticia/2016/08/04/ adimark-desaprobacion-de-bachelet-llego-a-73; https://mundo.sputniknews.com/americalatina/201608291063115988-chile-bachelet/ 
en el sondeo de julio-agosto. La Figura 1 muestra la evolución de la aprobación presidencial desde el año 2000 para mostrar el contexto en el que se sitúa el bajo apoyo a la jefe de Gobierno. Tal como advirtiera Castiglioni (2014: 80), la mandataria asumió el gobierno en el contexto de una sociedad civil movilizada y con expectativas de grandes transformaciones. Pero las expectativas pronto no fueron satisfechas; Bachelet solo gozó de más aprobación que rechazo en su primer año en el poder. Desde 2015, especialmente con la irrupción del caso Caval en febrero, experimentó un deterioro en el apoyo recibido.

Figura 1. Aprobación presidencial, 2000-2016

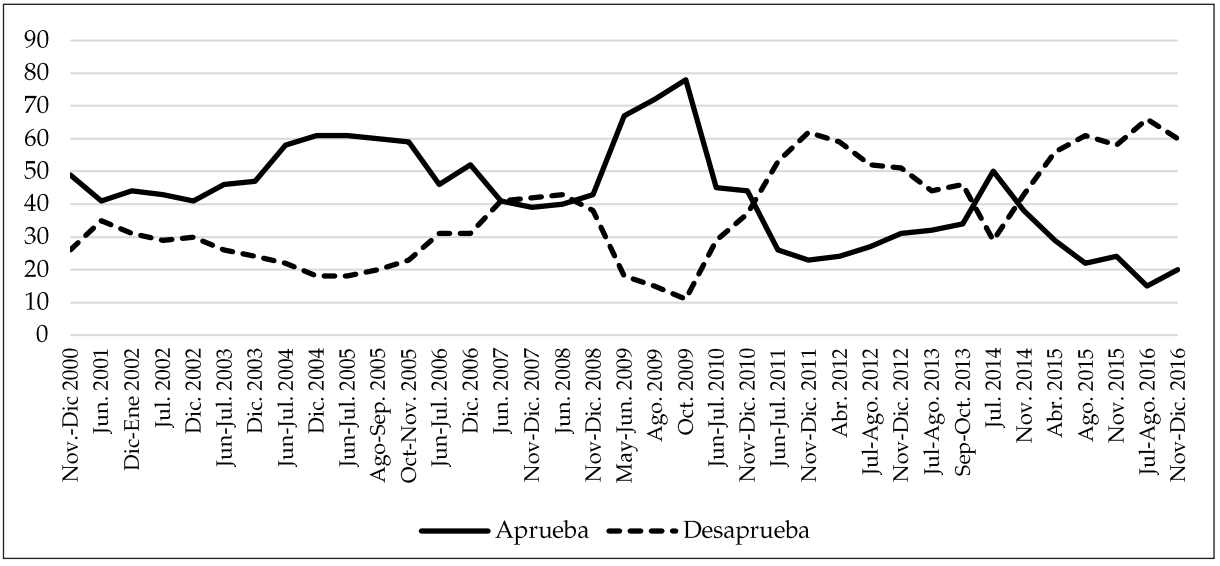

Fuente: CEP.

Al descrédito presidencial se suma la caída en la credibilidad en una serie de instituciones públicas. La Figura 2 muestra cifras categóricas. Los encuestados confían más que nada en las fuerzas de seguridad: Carabineros, Policía de Investigaciones y las Fuerzas Armadas. En 2016, la confianza en el gobierno (32\% en 2014, 15\% en 2015 y 10\% en 2016), en el Congreso (12\% en 2014, 6\% en $2015,4 \%$ en 2016) y en los tribunales de justicia (10\% en 2014, 7\% en 2015 y 2016) no superó el 10\% y fue la más baja registrada desde 2014 para los tres poderes del Estado. 
Figura 2. ¿Cuánta confianza tiene usted en cada una de ellas? (mucha + bastante)

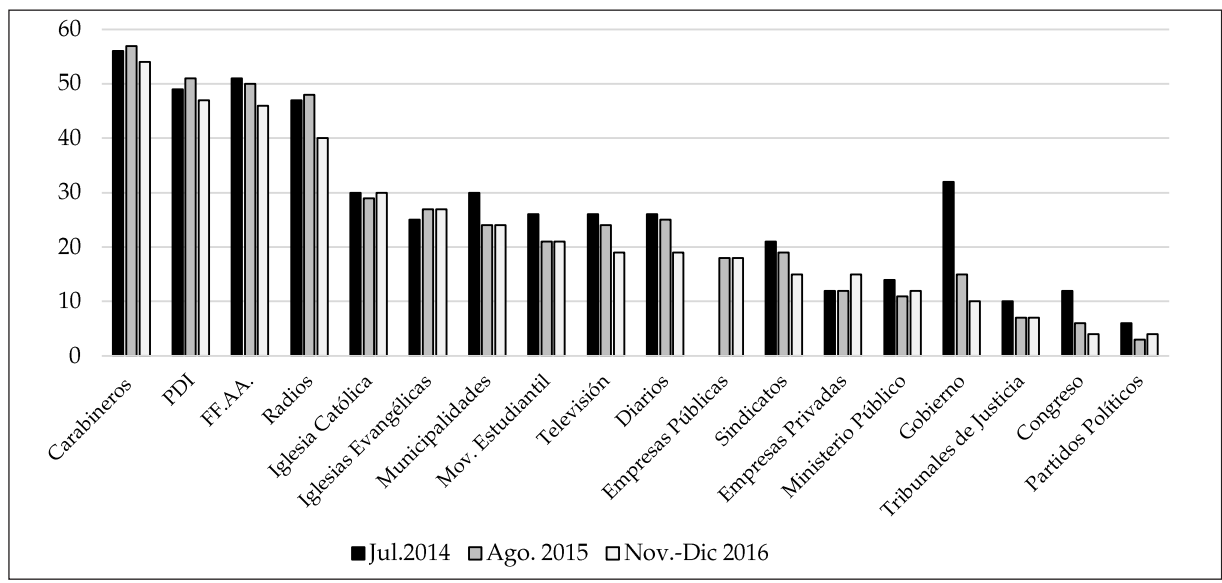

Fuente: CEP.

En consonancia con las anteriores, la Figura 3 muestra una pregunta que las encuestas del CEP han hecho de manera regular a los chilenos desde marzo-abril del año 2000. Como se aprecia, desde 2015, menos del 20\% de los encuestados cree que el país "progresa" y más del $60 \%$ sostiene que está "estancado". Aunque no es obvio, el desempeño gubernamental y la respuesta a la pregunta parecen ir de la mano. Desde 2014 la encuesta CADEM (2017) pregunta semanalmente a los encuestados si consideran que el país va por buen o mal camino. Al inicio del gobierno de Bachelet, ocho de cada diez encuestados respondía favorablemente. Dos años después, solo dos de diez mantenían la tendencia.

Figura 3. ¿Usted cree que en el momento actual Chile está: progresando, estancado o en decadencia?

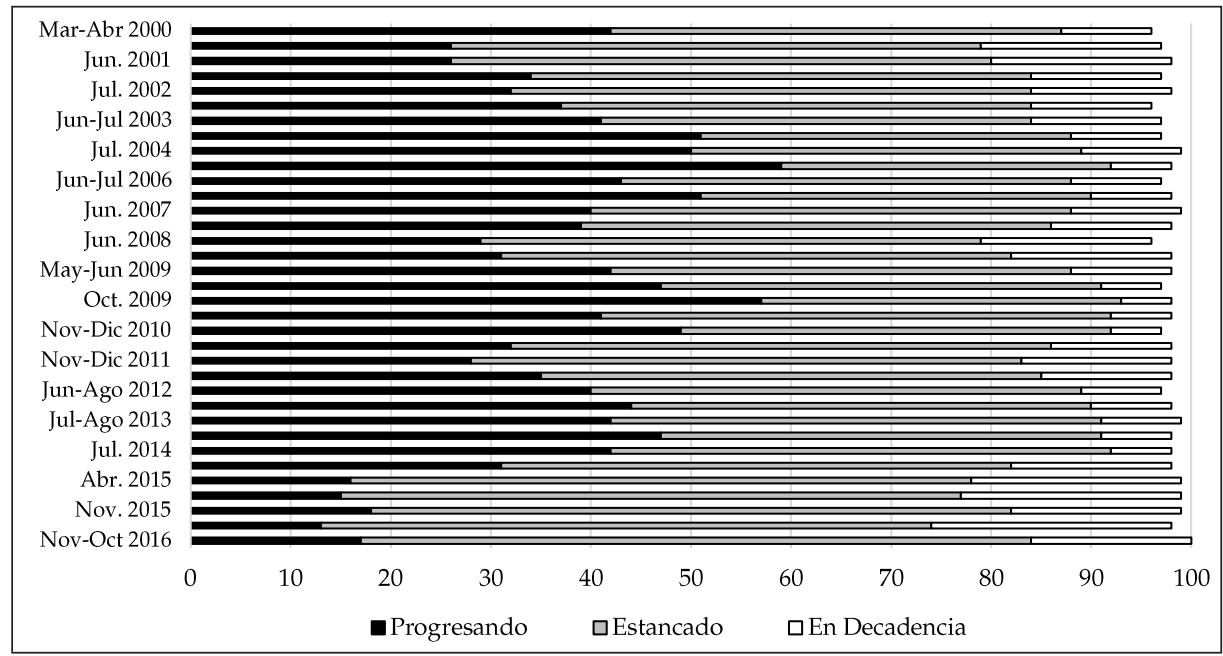

Fuente: CEP. 
La alta desconfianza generalizada en el gobierno y en las instituciones políticas es un fenómeno grave hace años. Tal como aseguraban Segovia y Gamboa (2012: 82) hace un lustro: "Los partidos y el gobierno aparecen desconectados de la ciudadanía y sus intereses. En este sentido, el 2011 dio señales de la existencia de un profundo problema de representación del sistema político chileno". Dicha desconexión alcanzó el punto más alto en 2016.

Otra manifestación de la poca legitimidad del sistema político es la baja identificación de las personas con los partidos. La siguiente figura muestra una tendencia en declive desde el año 2000, siendo 2016 el año en el que se llegó al punto más bajo (17\%).

Figura 4. Personas que se identifican con algún partido político.

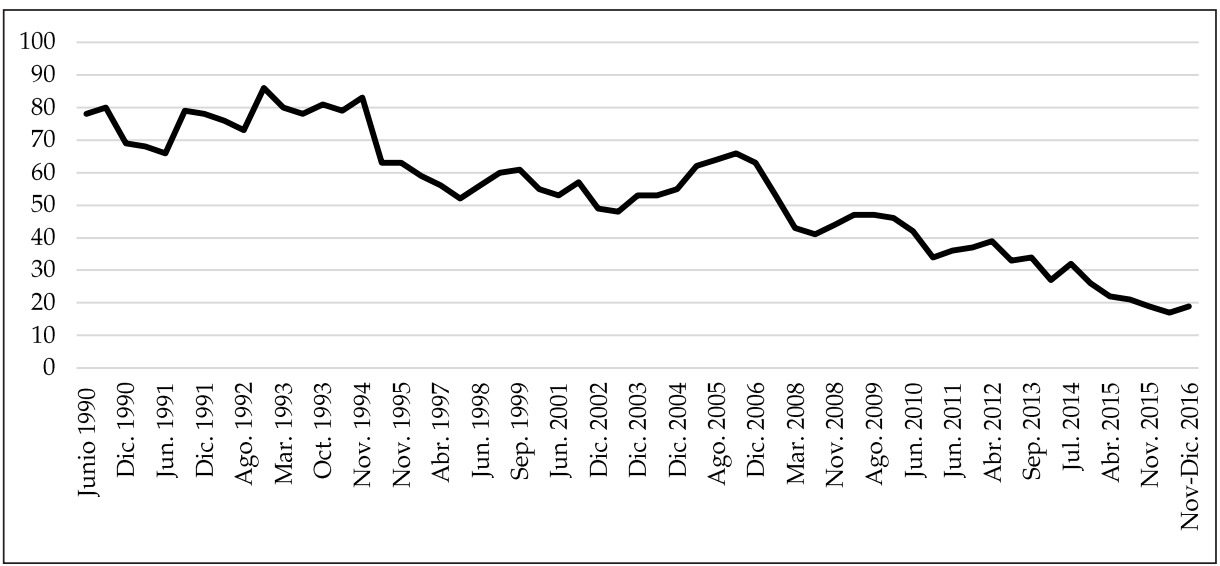

Fuente: CEP.

\section{Causas coyunturales: gestión gubernamental y escándalos de corrupción}

Dos problemas relacionados con la gestión gubernamental ayudan a entender la caída de la legitimidad. Primero, como se discutirá, hubo problemas de coordinación entre los partidos de la Nueva Mayoría, entre los actores en el Ejecutivo, y en las relaciones ejecutivo-legislativas. Las diferencias de opinión en el interior de la coalición hicieron que al gobierno le costara avanzar en sus proyectos pese a contar con mayoría legislativa. El segundo problema es que el gobierno ha conducido de manera errática las reformas educacional, laboral, constitucional, y tributaria. Dichas reformas han sido poco claras, la posición del gobierno ha cambiado, y se han dilatado en el tiempo a pesar de que estaban en la agenda desde que Bachelet asumió, en marzo de 2014.

La reforma tributaria demoró mucho en ver la luz. Tras ser discutida, la ley fue aprobada el 29 de septiembre de 2014 (Ley N ${ }^{\circ}$ 20.780), pero fue renegociada y en febrero de 2016 se promulgó la Ley 20.899 que modifica la reforma (T13 
2016, 1 de febrero). Durante todo ese tiempo, la complejidad de la reforma favoreció que tanto la oposición como dentro de la Nueva Mayoría criticaran distintos aspectos del proyecto, lo que hizo que tuviera una cobertura negativa en los principales medios de comunicación. La confusión e imprecisión también caracterizó a la reforma educacional. Aunque en 2015 el gobierno logró la aprobación de sus principales proyectos educacionales (Leyes 20.800 y 20.845), al cierre de 2016 existían 8 proyectos relacionados con la reforma siendo discutidos en el Congreso, o cuyo ingreso aún estaba pendiente. De manera similar, Bachelet pudo promulgar la nueva ley laboral (20.940) recién el 29 de agosto de 2016, y la reforma comenzó a regir el 1 de abril de 2017. El proyecto de reforma más difuso de todos es el constitucional. Aunque fue un tema discutido en la campaña presidencial de 2013-2014, el gobierno aún no envía al Legislativo una ley que lo habilite a decidir el mecanismo en el que se discutirá el proyecto de cambio a la Constitución en la legislatura que sea electa en los comicios de noviembre de 2017.

Otra de las potenciales causas para explicar la pérdida de legitimidad en el sistema político son los escándalos de corrupción en las élites políticas y económicas que se empezaron a destapar en 2015 (ver Gamboa y Segovia 2016) y que en 2016 continuaron en distintos ámbitos.

En enero, una auditoría reveló que seis diputados recibieron préstamos sin interés del Congreso (Radio Cooperativa 2016, 5 de enero). Aunque casi las únicas instituciones públicas en la que los chilenos confían son las fuerzas de seguridad, en 2016 el ejército y gendarmería protagonizaron escándalos. En febrero, los tribunales presentaron cargos por fraude tributario por primera vez a oficiales militares, en un escándalo que brotó en 2015 y que fue conocido como el "Milicogate". Este caso de corrupción implicó la desviación de fondos garantizados a las FF.AA. por la Ley Reservada del Cobre. En marzo se reveló que el exministro de Economía, Desarrollo y Turismo, Pablo Longueira, estaba siendo investigado por un intercambio de correos electrónicos con Patricio Contesse, el exgerente general de la empresa Soquimich (SQM), en donde se explicitaba que el gobierno incorporaría de manera textual una indicación propuesta por SQM a la Ley de Royalty. Longueira estuvo bajo arresto domiciliario nocturno y arraigo nacional entre el 22 de junio y el 21 de diciembre, mientras era investigado por presunto cohecho y fraude impositivo (Reuters 2016, 23 de junio; Radio Cooperativa 2016, 21 de diciembre). El resultado del proceso aún no estaba claro al cierre del año.

En mayo, la prensa reveló que el Contralor General descubrió que exempleados de Gendarmería, la fuerza policial a cargo de proveer seguridad en prisiones y en el sistema judicial, recibían ilegalmente pensiones muy altas (Rojas 2016, 17 de junio; Emol 2016, 10 de julio). Entre los beneficiados figuraban aquellos con influyentes contactos políticos. Como consecuencia, el director de Gendarmería, Tulio Arce, renunció. En junio, el senador UDI Jaime Orpis se transformó en el primer político desde 1990 enviado a prisión bajo acusaciones de corrupción. 
Orpis aceptó mensualmente pagos ilegales de Corpesca, la compañía de pesca más grande del país (Pulso 2016, 14 de octubre).

La cobertura mediática sobre los ilícitos fue alta en 2016. La Figura 5 muestra el número de veces que las palabras "corrupción" y "élite" fueron publicadas en el diario más influyente, El Mercurio, entre 1992 y 2016. ${ }^{2}$ De 2014 a 2015, "corrupción" subió de 834 menciones a 1488, situándose solo por debajo de 1994. Aunque en 2016 "corrupción" bajó a 1.219 menciones, siguió estando muy presente en el año (y por sobre 14 de los 24 años precedentes). El gráfico también muestra que el concepto "élite" se ha instalado con fuerza en los medios, de tal manera que desde 2012 superó las 300 menciones anuales y no bajó más de esa cifra. El uso incremental de este concepto sugiere que existe una mayor conciencia pública de que en la sociedad hay grupos selectos que concentran un alto poder de influencia sobre los demás. ${ }^{3}$

Figura 5. "Corrupción" y "élite" en El Mercurio

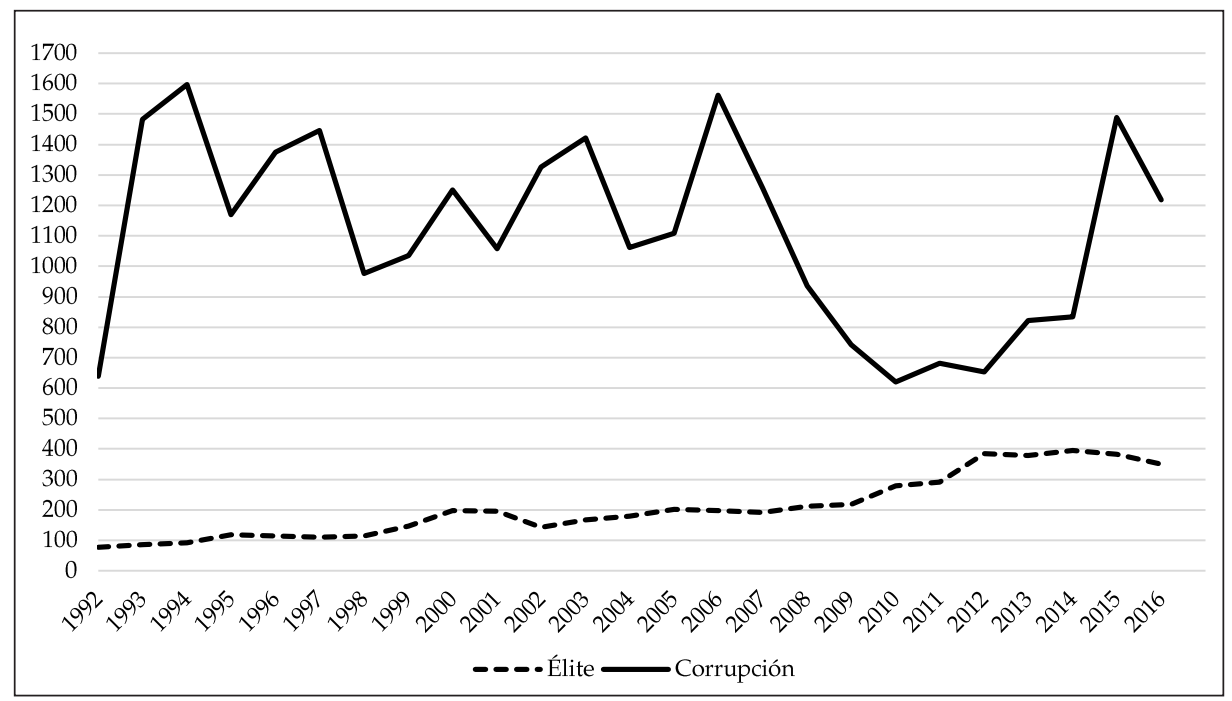

Fuente: Documentación de El Mercurio.

Precisamente, la profusión, diversidad, y seriedad de los escándalos de corrupción han extendido la imagen de que las élites usan posiciones en el Estado para engrosar sus bolsillos. Asimismo, existe la percepción de que los ilícitos permanecen impunes. Al preguntar sobre los "malos hábitos de los organismos públicos", La Encuesta Nacional de Transparencia (2015) reveló que la respuesta más repetida fue "corrupción" (19\%). En una escala donde "1" 
es no corrupto y " 10 " es completamente corrupto, el $69 \%$ de los encuestados le asignó 6 puntos o más a los organismos públicos. Del total, el 54\% de los encuestados afirmó que "mucha" gente está involucrada en la corrupción, y el $84 \%$ consideró que los actos corruptos "más bien quedan impunes". En resumen, los encuestados creen que la corrupción es sistémica y no se castiga. ${ }^{4}$

\section{Causas subyacentes: desconfianza interpersonal, desapego de la política y élites cerradas}

Tres causas que subyacen en la sociedad e interactúan con la contingencia parecen explicar la deslegitimidad del sistema político. Primero, la bajísima confianza interpersonal. La misma Encuesta Nacional de Transparencia (2015) reveló que el 88\% de los encuestados en 2015 (82\% en 2014) estuvo de acuerdo con que "no se puede confiar en la mayoría de las personas", mientras que sólo el 11\% (12\% en 2014) sostuvo lo contrario. Si la desconfianza en terceros es tan categórica, es improbable que la gente deposite su confianza en los líderes políticos.

Segundo, la desconfianza en la élite política parece responder a una alta desideologización de la sociedad civil. La siguiente figura revela que la mayoría de los encuestados no se identifica con una tendencia ideológica en el eje tradicional centro-izquierda. Esa fue la posición del 50\% de los encuestados en noviembre de 2014 y del 62\% dos años después. La opción que le sigue, centroizquierda más izquierda, nunca concitó más del 20\% del apoyo.

Figura 6. ¿Con cuál se identifica usted más o con cuál posición simpatiza usted más?

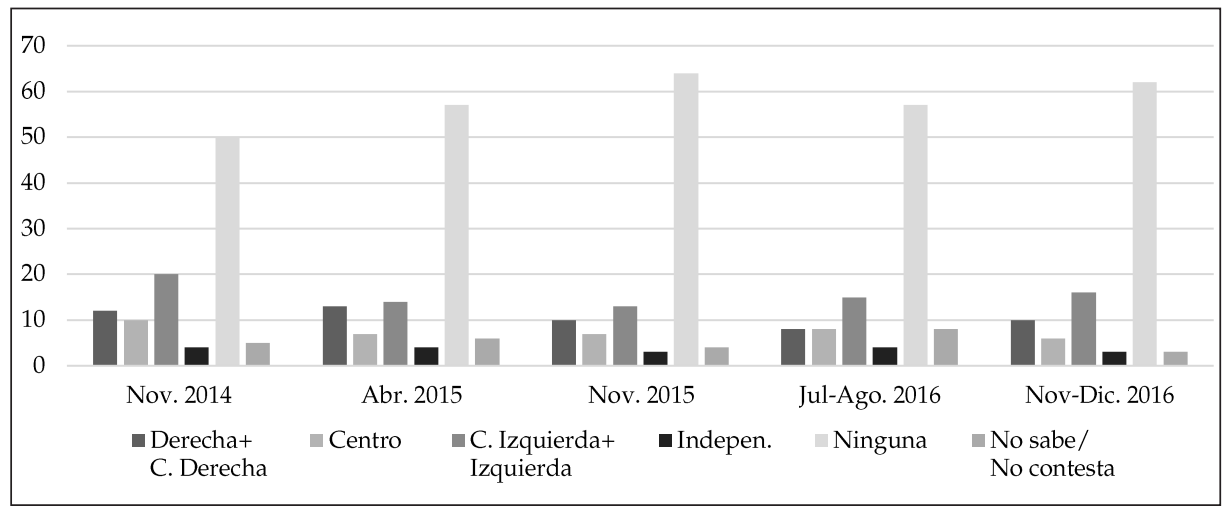

Fuente: CEP.

De manera similar, la encuestadora Cadem (2016) pidió a los encuestados que evaluaran la gestión del gobierno en una serie de áreas. De manera reveladora, de los 11 ítems consultados, el peor fuer la corrupción (90\% desaprueba; $8 \%$ aprueba). 
Si el electorado no tiene una preferencia sobre las ideas que separan a la izquierda de la derecha, difícilmente podrá inclinarse por apoyar un partido alineado ideológicamente, como es el caso de los partidos chilenos. La falta de una inclinación ideológica puede responder a que las personas desconocen las diferencias entre izquierda y derecha, o las conocen, pero no saben cómo posicionarse ante ellas. En cualquier caso, el desconocimiento sobre cómo funciona el sistema político parece ser una causa relevante: el $89 \%$ de los encuestados por la CEP 2016 declaró no saber que el sistema electoral para escoger legisladores cambiaría en 2017. Al provenir de quienes eligen a sus líderes políticos, tal ignorancia arriesga que los votantes elijan a candidatos que no representan sus preferencias.

Finalmente, la deslegitimidad del sistema político parece estar relacionada con la poca rotación de las élites. ${ }^{5}$ Esto se refleja en al menos tres hechos. Primero, desde 1990 solo un presidente, Patricio Aylwin, no ha buscado volver a La Moneda. Todos los siguientes o han regresado (Michelle Bachelet), o lo han intentado (Eduardo Frei Ruiz-Tagle), o anunciaron que lo intentarían (Ricardo Lagos y Sebastián Piñera). La falta de circulación en el pináculo de la política impide la emergencia de nuevos liderazgos y rigidiza el movimiento en las capas intermedias, ya que los liderazgos presidenciales se suelen sostener sobre una base relativamente estable de asesores y subalternos.

Segundo, la rotación de legisladores y alcaldes es muy baja. La tasa de reelección legislativa es la más alta de América Latina (BID, 2006). De acuerdo con Navia (2008), entre 1993 y 2001, el 73,3\% de los diputados buscaron la reelección, y el $82,2 \%$ de los que lo intentó fue reelecto. Y, al parecer, el puesto es bastante atractivo: el 15,8\% de los diputados electos en 1990 seguía en el Congreso un cuarto de siglo después (T13 2015, 11 de marzo). Evidentemente, dicha tasa de reelección ayuda al anquilosamiento de la élite política. La rotación no es mucho más alta a nivel local. Bunker (2008) muestra que entre 1996 y 2004 el 84,3\% de los alcaldes buscó la reelección, y el 57,5\% lo consiguió.

Finalmente, hay un estancamiento en los líderes de los partidos. Hay altos personeros de la Nueva Mayoría que han sido diputados, senadores, ministros, precandidatos presidenciales y líderes partidarios incluso desde antes de la dictadura militar. Tal es el caso del senador Andrés Zaldívar (81 años), quien tras rotar en distintos puestos de la élite política por medio siglo fue nombrado para presidir el Senado en 2017.

\section{Coyuntura económica}

En 2016 Chile creció solo un 1,6\%, la tasa más baja desde 2009 y menor al 2,1\% de 2015 y al 1,9\% de 2014 (Banco Central 2017). De acuerdo con el Informe de 
Cuentas Nacionales emitido por el Banco Central (2017: 5), "el resultado fue liderado por la actividad Servicios Personales, que destacó como el sector de mayor crecimiento e incidencia; aunque en menor medida, también destacó en términos de contribución, el sector Comercio. En tanto, los sectores Minería, Servicios empresariales, Industria manufacturera y Pesca registraron caídas, siendo los tres primeros los de mayor incidencia". El consumo de los hogares impulsó el gasto interno, que creció en 1,1\%, aunque la inversión cayó en 1,1\% debido a "una mayor desacumulación de existencias" y "una menor formación bruta de capital fijo" (Banco Central 2017: 8). En el comercio internacional, tanto las exportaciones como las importaciones sufrieron caídas en bienes, mientras que los servicios crecieron en exportaciones pero se contrajeron en importaciones.

Las causas tras el bajo crecimiento económico y contracción en la inversión tienen dos orígenes, uno internacional y otro interno. El argumento centrado en el exterior propone que la economía mundial aún no se recupera del todo de la crisis de 2008, lo que explica que el orbe está creciendo a dos puntos porcentuales menos que antes de ella. Asimismo, la desaceleración china ha generado una caída en la demanda mundial por materias primas, lo que ha afectado el precio del cobre, la principal exportación del país. El argumento centrado en el interior destaca que la inversión viene cayendo desde 2013 como consecuencia de la gestión gubernamental, especialmente debido a la incertidumbre generada por las reformas laboral y tributaria, el presunto mal uso de recursos públicos y la inquietud generada por las decisiones con consecuencias económicas que el gobierno podría tomar. Mientras los políticos y economistas cercanos al oficialismo enfatizan el contexto internacional, la contraparte de oposición enfatiza los factores domésticos. La mayoría de los analistas, en todo caso, parece asignarle valor explicativo a ambas hipótesis (Economía y Negocios 2016, 13 de diciembre).

A nivel de negocios, la agenda estuvo caracterizada por colusiones, escándalos financieros, y anuncios de grandes operaciones. En enero, la Fiscalía Nacional Económica denunció por colusión a Cencosud, Walmart y Unimarc. Las cadenas supermercadistas se habrían coludido en el mercado del pollo fresco entre 2008 y 2011, lo que fue negado por las compañías (FNE 2016, 6 de enero). En diciembre, Empresas CMPC, el holding forestal y papelero controlado por la familia Matte, reconoció que se coludió con la compañía Kimberly Clark entre 2002 y 2009 para subir el precio de algunos productos, incluyendo los pañales (T13 2016, 20 de diciembre). En 2016 hubo tres escándalos financieros ligados a estafas piramidales. En marzo se destapó la estafa piramidal de AC Inversions, que afectó a unas 5.000 personas. Ese mes también se supo de la estafa piramidal del inversionista Alberto Chang, quien se fugó a Malta tras la apropiación indebida de entre US \$85 y US\$ 100 millones (Economía y Negocios 2016, 20 de abril). El 23 de septiembre se conoció la desaparición del ingeniero comercial Rafael Garay, acusado de embaucar a decenas de clientes en una estafa piramidal con su empresa de inversiones Think \& Co (T13 2016, 22 de septiembre). 
En 2016 hubo varias fusiones y compras destacadas. El 15 de abril, la multitienda Falabella anunció un proyecto conjunto con la compañía mexicana Soriana para desarrollar Sodimac en el país del norte. Cada empresa se comprometió a aportar US\$ 300 millones en capital y bienes raíces en los siguientes cinco años (Bourlier 2016, 25 de abril). El 20 de abril, la distribuidora de gas Abastible compró el negocio de gas licuado de Repsol en Perú y Ecuador en US\$335 millones (Repsol 2016, 20 de abril). En julio, la cadena mexicana Liverpool anunció el lanzamiento de una Oferta Pública de Acciones por la multitienda Ripley (ebusinesshoy 2016, 28 de diciembre), mientras que Latam Airlines y Qatar Airways acordaron que la última tomaría el control del $10 \%$ de la aerolínea manejada por capitales chilenos y brasileños (LATA 2016, 12 de julio). En agosto, la bencinera Copec anunció la compra de las bencineras Mapco en Estados Unidos, por US\$ 535 millones (Burgos 2016, 29 de agosto). En septiembre, la aseguradora Confuturo cerró la compra de los 10 malls Espacio Urbano a Walmart, por US\$ 645 millones, mientras que la empresa estadounidense Advent International compró el 30\% de la firma operadora de casinos y hoteles Enjoy, por US\$ 77 millones (Economía y Negocios 2016, 2 de septiembre, 21 de septiembre).

\section{Coyuntura subregional e internacional}

En el frente internacional hubo cuatro temas destacados: una ofensiva comunicacional por parte de la Cancillería para posicionar la imagen de Chile en el exterior, una estrecha relación con los nuevos gobiernos de Perú y Argentina, la mantención de tensiones con el gobierno boliviano, y una agenda presidencial activa en reuniones con líderes mundiales.

El Ministerio de Relaciones Exteriores publicó el libro Vocación de paz. La Política Exterior de Chile, un texto de 220 páginas que presenta todos los aspectos relevantes de la política exterior del país, e incluye detalles sobre tratados, postales, estampillas, fotografías y citas famosas. El propósito central fue promover la idea de que Chile es un país global y culturalmente rico. Dicho libro comenzó a ser entregado a autoridades extranjeras en la Cumbre Presidencial de la Alianza del Pacífico celebrada en julio en Puerto Varas (Economía y Negocios 2016, 26 de junio).

Las relaciones con Argentina y Perú fueron particularmente positivas. A nivel oficial, las relaciones con Argentina se reactivaron cuando el Presidente Mauricio Macri visitó a Bachelet en diciembre de 2015, antes de asumir la primera magistratura. En 2016 se realizó la reunión 2+2 entre los cancilleres y ministros de Defensa de ambos países, lo que no ocurría desde el 2011, y se reactivó el comité empresarial bilateral (Rodillo 2016, 9 de diciembre). En octubre, los congresos de ambos países ratificaron el Convenio de Doble Tributación, el cual desde el primero de enero de 2017 eliminará la doble imposición en los impuestos sobre la renta y sobre el patrimonio y también previene la evasión y elusión fiscal (La Tercera 2016, 17 de octubre). Al cerrar el año, Bachelet y 18 
de sus 22 ministros se reunieron con Macri y altos personeros trasandinos en Buenos Aires (infobae 2016, 16 de diciembre). Tal concurrencia buscó demostrar la importancia de la relación bilateral, especialmente cuando Argentina preside el Mercosur y Chile tiene la presidencia pro témpore de la Alianza del Pacífico (integrada por Chile, Colombia, Perú y México), grupo al cual Bachelet pidió a Macri que sumara a su país. En la reunión bilateral también se abordó empezar en 2017 la licitación de la construcción del Túnel de Agua Negra, una obra de US\$ 1.600 millones que unirá la provincia argentina de San Juan con la región de Coquimbo.

Las relaciones con Perú también se dinamizaron. Bachelet se reunió en julio por primera vez con el entonces presidente electo, Pedro Pablo Kuczynski, en el marco de la XI Cumbre de la Alianza del Pacífico que se realizó en la ciudad de Puerto Varas. Kuczynski expresó su interés en restablecer el mecanismo de diálogo bilateral conocido como " $2+2$ ", y que reúne a los cancilleres y los ministros de Defensa de ambos países. Luego de la cumbre de noviembre del Foro Económico Asia-Pacífico (APEC) en Lima, Bachelet recibió nuevamente a su par peruano, con quien firmó un nuevo Tratado de Extradición; un Memorándum de Entendimiento para establecer un Mecanismo de Diálogo y Cooperación en materia de Derechos Humanos; y un Acuerdo Interinstitucional entre las Agencias de Cooperación de ambos países (Gestión 2016, 29 de noviembre). Ambos líderes también acordaron crear un gabinete binacional de ministros en junio de 2017, y solicitaron a sus ministros de Energía elaborar una propuesta de interconexión eléctrica.

La tensa interacción con Bolivia contrastó con las relaciones con los otros países limítrofes. El 23 de marzo, el día que Bolivia celebra el Día del Mar, el Presidente Evo Morales anunció una demanda contra Chile por el presunto uso ilegal de las aguas del río Silala. A través del canciller Heraldo Muñoz, Chile respondió que el Silala es un río internacional de aguas compartidas al que tiene derecho a uso y que en caso de ser demandado el país podría contrademandar (Fernández 2016, 24 de marzo). Tres días más tarde, Morales planteó que recurriría a la Corte Internacional de Justicia de la Haya, pero finalmente fue Chile el que demandó a Bolivia ante dicha corte para que se pronuncie sobre si el río es internacional, como dice Chile, o no (BBC 2016, 6 de junio). El resto del año se caracterizó por diatribas de Morales hacia Chile, las que no fueron contestadas o fueron respondidas por Muñoz.

La agenda internacional con países no limítrofes se caracterizó por la reunión de Bachelet con líderes mundiales y la firma de acuerdos bilaterales. En febrero, Bachelet se reunió con el Presidente de Turquía, Recep Tayyip Erdogan, con quien firmó en Santiago un acuerdo entre la Agencia de Cooperación y Coordinación de Turquía (TIKA) y la Agencia de Cooperación Internacional para el Desarrollo de Chile (AGCI) (El Comercio 2016, 2 de febrero). En el mismo mes, Bachelet recibió en Santiago la visita protocolar de la Presidente de Brasil, Dilma Rousseff (DW 2016, 27 de febrero). En junio, Bachelet se reunió en el Palacio del Elíseo con el Presidente de Francia, François Hollande, con 
quien revisó los avances en los acuerdos de cooperación que firmaron en la anterior visita de Bachelet a París, doce meses antes. Hollande destacó que su gobierno buscaba ampliar las inversiones francesas en "start ups" radicadas en Chile (von Baer 2016, 3 de junio). En noviembre, Bachelet participó en la cumbre APEC, donde llamó a los 21 países del bloque a consolidar un área de libre comercio (Vargas 2016, 20 de noviembre). Allí se reunió por última vez con su par estadounidense, Barack Obama. En la cumbre, la legación chilena defendió con ahínco el Acuerdo Transpacífico (TPP). ${ }^{6}$ El canciller Heraldo Muñoz dijo que, de no materializarse el TPP, Chile apoyaría la futura área de libre comercio de Asia Pacífico bajo el liderazgo chino. Tras el encuentro, Bachelet se reunió en Santiago con el presidente de la República Popular China, Xi Jinping, con quien firmó 12 acuerdos comerciales y de cooperación, incluyendo una profundización del tratado de libre comercio bilateral de 2004 (Álvarez 2016, 22 de noviembre).

\section{CAMBIOS EN INSTITUCIONES Y POLÍTICAS PÚBLICAS}

En 2016 hubo, se avanzó o se anunciaron al menos cinco cambios institucionales significativos. Uno de ellos, el anuncio de la creación de dos nuevos ministerios, consolidaría la expansión de la estructura administrativa del Estado bajo el gobierno de Bachelet, quien sumaría cuatro ministerios en su segundo mandato. Segundo, la reforma laboral cambió la relación entre empleadores y trabajadores. Tercero, los trabajadores también vieron un incremento en su protección social luego de que el gobierno propusiera aumentar la tasa de cotización. Un cuarto cambio avanza paralelamente con la propuesta gubernamental de elegir directamente a intendentes. De todos los cambios institucionales, el más incierto es también aquel con la potencialidad de generar las variaciones más significativas en la estructura del Estado y en las reglas de convivencia de la sociedad: el proyecto de sustituir la constitución.

Bachelet propuso en enero crear el Ministerio de Asuntos Indígenas y el Ministerio de Ciencia y Tecnología (Álvarez 2016, 19 de enero). El primero, cuyo proyecto de ley fue firmado por Bachelet ese mismo mes, tiene como objetivo central implementar la nueva Política Nacional Indígena. El segundo ministerio, cuyo proyecto de ley fue firmado en enero de 2017, buscará colocar la generación de conocimiento e innovación en el centro del modelo de desarrollo a través de una mejor coordinación de las políticas de la actual Comisión Nacional de Investigación Científica y Tecnológica (Conicyt). Ambos ministerios se suman al proyecto de ley enviado por el gobierno al Congreso en diciembre de 2015, en el que se propone crear el ministerio de Cultura y las Artes. Los tres nuevos ministerios se sumarían a otro propuesto por el gobierno de Bachelet, el Ministerio de la Mujer y Equidad de Género, aprobado por el Congreso en

Pocas semanas después, el sucesor de Obama, Donald Trump, anunciaría el retiro del acuerdo el 23 de enero de 2017, apenas tres días después de jurar como presidente. 
marzo de 2015. Si se avanza en estos cambios, el gobierno de Bachelet cerraría su mandato con 25 secretarías de Estado, cuatro más que las 21 que recibió del expresidente Sebastián Piñera.

Bachelet promulgó la Ley 20.940 sobre la reforma laboral el 29 de agosto (Marchetti 2016, 29 de agosto). Esta reforma, que comenzaría a regir el 1 de abril de 2017, busca mejorar las relaciones entre empleadores y trabajadores. Genera al menos ocho cambios clave. Primero, amplía la negociación colectiva, permitiendo que participen los trabajadores que se desempeñen en una obra o faena transitoria. Segundo, amplía las materias a negociar al garantizar que se puedan negociar todos los temas de interés común de las partes. Tercero, permite a los trabajadores de empresas donde al menos el $30 \%$ esté sindicalizado a trabajar cuatro días a la semana. Cuarto, faculta a los sindicatos a acordar que trabajadores con problemas familiares se acojan a regímenes especiales de trabajo (como laborar desde la casa). Quinto, exige un 30\% de participación femenina en los directorios sindicales. Sexto, pone fin al reemplazo de los trabajadores en huelga, excepto en condiciones donde la falta de reemplazos produzca daños mayores. Séptimo, reconoce a los sindicatos interempresa, aunque para micro y pequeñas empresas será voluntario negociar con dicho sindicato. Octavo, las grandes empresas deberán informar a sus sindicatos cada año su estado de resultados, el balance general, los estados financieros auditados, y las remuneraciones de empleados en puestos ejecutivos.

Un tercer cambio está relacionado con las pensiones. El 9 de agosto Bachelet comunicó que, con el objetivo de mejorar las pensiones de los trabajadores, la tasa de cotización aumentará de un $10 \%$ a un $15 \%$ de la renta, con aporte del empleador. El anuncio se produjo después de una marcha de cientos de miles de personas en todo el país en la que pidieron mejorar las pensiones (T13 2016, 1 de enero). La marcha, organizada por la organización "No+AFP", demostró el descontento acumulado con las magras jubilaciones que el sistema de AFPs genera. Vinculado a las pensiones, tras un corto proceso de tramitación en el Legislativo, en noviembre el gobierno promulgó una ley que reajusta la Pensión Básica Solidaria en un $10 \%$, pasando de $\$ 93.543$ a $\$ 102.897 .7$

Con el fin de descentralizar la estructura del Estado y democratizar la elección de puestos gubernamentales, a fines de diciembre Bachelet promulgó una ley que introduce la elección directa de intendentes (T13 2016, 29 de diciembre). De acuerdo con el proyecto, los intendentes pasarán a llamarse "gobernadores regionales", necesitarán ganar con al menos un $40 \%$ de los votos y solo se podrán repostular una vez al cargo de cuatro años.

Finalmente, en 2016 hubo cambios en el -incierto- proceso constituyente. Entre octubre de 2015 y marzo de 2016 el gobierno lideró instancias de formación ciudadana sobre temas constitucionales para generar una participación

Esta pensión es un beneficio monetario mensual al que pueden acceder todas las personas que no tengan derecho a una pensión en algún régimen previsional, y favorece a 1,4 millones de personas. 
informada en la creación de las bases de una nueva Constitución. Entre abril y junio de 2016 se realizó la etapa participativa del proceso a través de "diálogos ciudadanos" desarrollados en encuentros locales y cabildos provinciales y regionales. La etapa concluyó con la elaboración de las "bases ciudadanas para la Constitución", que se supone recogió los acuerdos y desacuerdos de los participantes. El Consejo de Ciudadanos Observadores, integrado por quince miembros de la sociedad civil nombrados por Bachelet, observó los diálogos y redactó un informe sobre sus resultados. El gobierno usará como base ese reporte para enviar un proyecto de reforma constitucional al Congreso en algún momento de 2017. El plan es que el Congreso decida si habilitará a la legislatura del período 2018-2022 para que escoja un mecanismo de discusión y aprobación de un eventual cambio constitucional.

\section{ELECCIONES}

El 23 de octubre de 2016 se celebró la trigésimo tercera elección municipal para escoger 345 alcaldes y 2.240 concejales, quienes duran cuatro años en sus cargos. Se presentaron 1.211 candidatos a alcalde y 13.130 a concejal. ${ }^{8}$ Estas fueron las segundas elecciones bajo la modalidad de inscripción automática y voto voluntario. ${ }^{9}$

La Nueva Mayoría presentó dos listas de concejales, una integrada por el Partido Democráta Cristiano (PDC) y el Partido Socialista (PS), y la otra por el Partido por la Democracia (PPD), el Partido Radical Social Demócrata (PRSD) y el Partido Comunista (PC). La coalición de centroderecha, denominada Chile Vamos, presentó tres listas separadas: una para la Unión Demócrata Independiente (UDI), otra para Renovación nacional (RN), y otra para Evolución Política (Evópoli) y el Partido Regionalista Independiente (PRI).

Más allá de los resultados, hubo dos aspectos particularmente llamativos de esta elección. Primero, el Registro Civil cambió por error el domicilio electoral de 485.000 personas (3,4\% de los votantes), quienes debieron sufragar en otras comunas. Los problemas se arrastraban desde el 2013, tras una renovación del sistema tecnológico del Registro Civil (Vargas 2016, 13 de octubre). El problema generó desacuerdos entre este órgano estatal y el Servicio Electoral (Servel), y también se discutió la posibilidad de postergar la elección, pero finalmente el Congreso decidió mantener el cronograma. Segundo, en la contienda solo participó el 34,9\% de los votantes (4,9 millones de 14,1 millones), registrando el mayor abstencionismo electoral desde 1990 en Chile. Debido a estos resultados, varios analistas y políticos reflotaron la posibilidad de reinstaurar el voto obligatorio (Campos y Becerra 2016, 23 de octubre).

$8 \quad$ Las comunas con hasta 70 mil inscritos escogen 6 concejales; las que tienen entre 70 mil y 150 mil eligen 8 ; y las que superan los 150 mil votantes escogen 10 concejales.

9 En algunas comunas aumentó la cantidad de concejales a elegir, ya que su número depende del número de votantes inscritos. En total se escogieron 16 concejales más que en 2012. 
Chile Vamos ganó 145 alcaldías y 916 concejales, mientras que la Nueva Mayoría le siguió con 141 alcaldías y 1.208 concejales. Ambas coaliciones sumaron fue el $83 \%$ de las alcaldías. Los candidatos independientes se consolidaron como la tercera gran fuerza: ganaron 52 alcaldías, 11 más que en 2012. La interpretación de los resultados en la prensa nacional e internacional fue que la derecha política creció, arrebatándole a la Nueva Mayoría comunas emblemáticas como Santiago, Providencia y Maipú, y reteniendo Las Condes, Vitacura, Viña del Mar, Temuco y Ñuñoa (Campos y Becerra 2016, 23 de octubre; El Mundo 2016, 25 de octubre). La UDI obtuvo 52 alcaldes y RN 47. En la Nueva Mayoría los resultados fueron 43 alcaldes PDC, 26 PPD, 25 PS y 9 PRSD. Tal vez el partido que más perdió respecto de las elecciones de 2012 fue el Partido Progresista (PRO) liderado por Marco Enríquez-Ominami, cuya coalición también incorporaba a la Democracia Regional Patagónica (DRP), al Frente Regional y Popular (FR), y Wallmapuwen. Solo obtuvieron 2 alcaldías y 38 concejales, tras postular a 66 alcaldías y 1.093 concejalías. En 2012 el PRO lideró una coalición que obtuvo 7 alcaldías y 45 concejales.

Las elecciones siguieron la tradición de tener un fuerte sesgo de género. De acuerdo con el PNUD (2016), solo hubo un 19\% de candidatas a alcalde y $30.9 \%$ a concejalas. Aunque el número representa una mejora de $4 \%$ en candidatas a alcaldesa y 5\% en aspirantes a concejala respecto de las municipales de 2012, las mujeres siguen siendo fuertemente subrepresentadas. Asimismo, las candidatas fueron menos competitivas que sus pares masculinos: solo el 11,9\% de las aspirantes a alcaldesa y el $24,6 \%$ de las candidatas a concejala resultó electa (PNUD 2016: 7). Un aspecto interesante en el sesgo de género es que en 51\% de las comunas no hubo candidatas.

Aunque muchas veces las municipales son interpretadas como una antesala de los resultados de las elecciones legislativas y presidenciales siguientes (en este caso en 2017), es riesgoso sobreinterpretar los resultados con una participación electoral tan magra. Pero ellos permiten delinear algunos aspectos del próximo escenario electoral. Primero, la correlación de fuerzas entre las dos principales coaliciones es similar. Segundo, la baja participación sugiere que los próximos resultados podrán depender en gran medida de la capacidad de los partidos para movilizar a votantes indiferentes, lo que abre un escenario de alta incertidumbre electoral. Tercero, tanto el ausentismo electoral como el alto número de independientes que triunfaron sugieren que hay mucho espacio para la irrupción de nuevos partidos y coaliciones de partidos. Como se describió, los partidos políticos y los legisladores actuales padecen un altísimo descrédito entre los votantes, lo que ofrece una oportunidad para proyectos y actores nuevos. Cuarto, el sesgo de género sugiere que si no cambia la normativa para forzar un mayor número de candidatas y no hay un esfuerzo para ampliar su distribución geográfica, los progresos que se pueden esperar en igualdad de género son mínimos. 


\section{PODERES EJECUTIVO Y LEGISLATIVO}

\section{Ejecutivo}

Las relaciones intraejecutivo fueron testigo de tensiones entre Bachelet y sus ministros, y entre el gobierno y los partidos de la Nueva Mayoría. Como consecuencia, hubo rotaciones ministeriales y llamados de atención por parte de la presidenta a su gabinete. En febrero, por ejemplo, la prensa reportó que Bachelet exigió a sus ministros actuar con mayor disciplina, coordinación y trabajo en equipo (Canales y Fernández 2016, 22 de febrero). Esto ocurrió luego de que el exadministrador de La Moneda, Cristián Riquelme, fuera despedido tras cometer una serie de irregularidades, y cuya salida reveló una descoordinación entre los secretarios de Estado.

Elcambio más importante en el gabinete fuela renuncia que presentó el demócrata cristiano Jorge Burgos a la cartera de Interior el 8 de junio, tras haber asumido en mayo de 2015. Burgos tuvo diferencias importantes con Bachelet durante su gestión. En diciembre de 2015 el ministro presentó por primera vez su renuncia luego de que Bachelet no lo incluyera en una sensible visita presidencial a la Región de la Araucanía. La presidenta la rechazó. Según el diario La Tercera, tras el episodio, Burgos le transmitió a Bachelet que su partido consideraba que su jefa de Gabinete, Ana Lya Uriarte, y su jefa de Comunicaciones, Haydée Rojas, mantenían en un permanente aislamiento a la mandataria (López y Artaza 2016, 10 de enero). Ese mismo mes Burgos contradijo la política del gobierno de no referirse al caso de la empresa Caval, al comentar declaraciones del hijo de Bachelet, Sebastián Dávalos. ${ }^{10}$ Luego, en marzo de 2016, Burgos expresó dudas sobre la idoneidad del proyecto gubernamental de despenalización del aborto (Núñez y Carrasco 2016, 21 de marzo).

La coordinación intraejecutivo y entre el Ejecutivo y los partidos de la Nueva Mayoría no pareció mejorar mucho tras la salida de Burgos. En octubre, el flamante ministro del Interior y también DC, Mariano Fernández, pidió perdón tras irrumpir en la discusión sobre los precandidatos presidenciales al decir que "la decisión (presidencial), a la larga, va a ser entre Lagos y Piñera; lo otro es fantasía, poesía" (Fuentes y von Baer 2016, 14 de octubre). Bachelet y la presidenta de la DC, Carolina Goic, le recriminaron a Fernández la declaración. Asimismo, el Partido Radical, el cual postulaba al periodista Alejandro Guillier como precandidato, exigió la renuncia del ministro. Fernández no fue el único secretario de Estado que opinó sobre los precandidatos presidenciales. El vocero de gobierno, Marcelo Díaz, dijo que le parecía "natural" y "sensato" que el PS y el PPD tuvieran un candidato presidencial único. Ante esto, Bachelet reprochó nuevamente en público a sus ministros y pidió no intervenir en el debate sobre precandidatos presidenciales (Álvarez y Carreño 2016, 13 de octubre).

10 Dávalos habría ejercido tráfico de influencias para que la empresa Caval obtuviera un crédito por US\$ 10 millones del Banco de Chile. Para más información ver Cádiz (2016, 8 de junio). 
Bachelet hizo dos modificaciones menores a su gabinete. El 19 de octubre anunció la salida de tres de sus ministros: Javiera Blanco (DC, Justicia), Máximo Pacheco (PS, Energía) y Víctor Osorio (IC, Bienes Nacionales). En su reemplazo ingresaron Jaime Campos (PR) a Justicia, Andrés Rebolledo (PS) a Energía y Nivia Palma (IC) a Bienes Nacionales. Dicho cambio reflejó el estilo de liderazgo secretista de Bachelet. Su anuncio se produjo a las cuatro de la tarde, pero hasta pasado el mediodía el comité político de La Moneda -integrado por los ministros de Interior, Secretaría General de Gobierno y Secretaría general de la Presidencia- no sabía de todos los cambios (Ahumada y von Baer 2016, 20 de octubre).

El 18 de noviembre se produjo otro cambio en el gabinete, luego de que Bachelet pidiera que los ministros con intenciones de postularse al Congreso en 2017 renunciaran. Tras esta petición, dimitieron el ministro Secretario General de Gobierno, Marcelo Díaz (PS), la ministra de Trabajo, Ximena Rincón (DC), y la ministra del Deporte, Natalia Riffo (MAS) (Vargas y Blanco 2016, 18 de noviembre). Díaz fue reemplazado por la sicóloga Paula Narváez (PS), mientras que la exministra de Planificación Alejandra Krauss (DC) asumió en el ministerio de Trabajo y el exatleta Pablo Squella asumió en Deportes.

Otro cambio importante en el Ejecutivo se produjo en octubre, cuando Bachelet reemplazó a siete de los 32 subsecretarios en reacción a los negativos resultados de las elecciones municipales. Los políticos entrantes reemplazaron a miembros de sus mismos partidos. En el PS, Patricia Silva (Segpres) y Jaime Romero (Vivienda) fueron reemplazados por Gabriel de la Fuente e Iván Leonhardt, respectivamente. Entre los subsecretarios PPD, Antonio Frey (Prevención del Delito) fue reemplazado en calidad de subrogante por Rodrigo Asenjo, mientras que a Pedro Huichalaf, de Telecomunicaciones, lo sucedió Rodrigo Ramírez. En Previsión Social, en tanto, la comunista Jeanette Vega reemplazó a Julia Urquieta. En la DC, Nicolás Mena asumió en Justicia en reemplazo de Ignacio Suárez, y Omar Jara ingresó a la Segegob, cargo que se encontraba vacante. Estos cambios ayudaron a apaciguar las críticas internas en la Nueva Mayoría, pero no parecieron tener un impacto sobre la coordinación dentro de la coalición.

\section{Legislativo}

La elección parlamentaria de 2013 le entregó la mayoría legislativa a la Nueva Mayoría en ambas cámaras. Pero los problemas de coordinación entre ambos poderes del Estado, como se discute en la siguiente sección, han puesto trabas a la agenda legislativa del gobierno. La tabla que sigue muestra la composición del Legislativo. 
Tabla 1. Conformación de la Cámara de Diputados y del Senado (2014-2018)

\begin{tabular}{lcc}
\hline \multicolumn{1}{c}{ Partido } & Cámara de Diputados & $\begin{array}{c}\text { Senado } \\
\mathrm{N}(\%)\end{array}$ \\
\hline Partido Comunista (PC) & $\mathrm{N}(\%)$ & $6(15.8 \%)$ \\
Partido Socialista (PS) & $16(13.3 \%)$ & $1(2.6 \%)$ \\
Partido Movimiento Amplio Social (MAS) & & \\
Izquierda Ciudadana (IC) & $1(0.8 \%)$ & \\
Revolución Democrática (RD) & $1(0.8 \%)$ & $6(15.8 \%)$ \\
Partido por la Democracia (PPD) & $14(11.7 \%)$ & $7(18.4 \%)$ \\
Partido Radical Social Demócrata (PRSD) & $6(5 \%)$ & \\
Partido Demócrata Cristiano (PDC) & $20(16.7 \%)$ & \\
Partido Liberal de Chile (PL) & $1(0.8 \%)$ & \\
Amplitud & $2(1.6 \%)$ & $5(13.6 \%)$ \\
Evópoli & $1(0.8 \%)$ & $6(15.8 \%)$ \\
Independientes & $8(6.7 \%)$ & $7(18.4 \%)$ \\
Renovación Nacional (RN) & $15(12.5 \%)$ & 38 \\
Unión Demócrata Independiente (UDI) & $29(24.2 \%)$ & \\
Total & 120 & \\
\hline
\end{tabular}

Fuente: www.senado.cl y www.camara.cl.

La siguiente tabla muestra tanto la productividad del cuerpo legislativo en términos de presentación de mensajes y mociones, así como de aprobación de leyes durante los tres años legislativos bajo el gobierno de Bachelet. Como se aprecia, pese a que el número de proyectos de ley presentados decayó, el total de leyes publicadas fue idéntico al del año anterior. El cambio más interesante que se observa, sin embargo, es en la dinámica de las iniciativas de ley presentadas por el Ejecutivo (mensajes) y el Legislativo (mociones). En 2016 el Ejecutivo quintuplicó el número de proyectos de ley enviados, mientras que el Legislativo presentó casi el 10\% de lo propuesto en 2015. Lo anterior sugiere que 2016 fue el año en el que el gobierno más trató de avanzar en sus propuestas, tal vez anticipando una mayor resistencia en el año electoral 2017. 
Tabla 2. Cifras de la Labor Legislativa (2014-2016)

\begin{tabular}{lccc}
\hline & 2014 & 2015 & 2016 \\
\hline Proyectos Ingresados & $\mathrm{N}(\%)$ & $\mathrm{N}(\%)$ & $\mathrm{N}(\%)$ \\
\hline Moción & $442(82.8 \%)$ & $531(83.1 \%)$ & $59(10.5 \%)$ \\
Mensaje & $92(17.2 \%)$ & $108(16.9 \%)$ & $504(89.5 \%)$ \\
Total & 534 & 639 & 563 \\
\hline Leyes Publicadas & & & \\
\hline Moción & $41(36 \%)$ & $42(38.5 \%)$ & $45(41.3 \%)$ \\
Mensaje & $73(64 \%)$ & $67(61.5 \%)$ & $64(58.7 \%)$ \\
Total & 114 & 109 & 109 \\
\hline
\end{tabular}

Fuente: Cámara de Diputados (2014-2016).

Pese a la poca confianza pública en el Congreso, el Legislativo chileno obtuvo el segundo lugar en el Índice de Transparencia Legislativa 2016 (Red Latinoamericana por la Transparencia Legislativa S.f.). El índice midió qué tan abiertos a la ciudadanía fueron trece congresos latinoamericanos. ${ }^{11}$ De acuerdo con el estudio, Chile fue el único país evaluado que regula el lobby. Sin embargo, mostró un retraso en áreas como vías de participación ciudadana en el proceso legislativo, en el despliegue territorial más allá de Santiago y Valparaíso, y en la información pública referente al Senado.

\section{Relación Ejecutivo-Legislativo}

El año partió con intentos en la Nueva Mayoría por mejorar las relaciones Ejecutivo-Legislativo (Ahumada y von Baer 2016, 5 de enero). En enero los ministros del comité político y los presidentes de los partidos de la Nueva Mayoría se reunieron por horas para minimizar las descoordinaciones que caracterizaron al año precedente, como la visita de Bachelet a la Región de la Araucanía de la que no fue informado su ministro del Interior. En dicha reunión los ministros se comprometieron a visitar el Legislativo para discutir la agenda gubernamental y sostener un diálogo más fluido con los partidos.

Pero las tensiones se hicieron evidentes a lo largo del año, especialmente debido a la baja popularidad del gobierno. Eso se reflejó en particular a fines de año, cuando los líderes de los partidos de la Nueva Mayoría solicitaron múltiples veces la salida de los ministros que componían el comité político de La Moneda: los ministros Marcelo Díaz (secretario General de Gobierno), Nicolás Eyzaguirre (secretario General de la Presidencia) y Mario Fernández (Interior) (Marín 2016, 27 de octubre). En octubre, legisladores oficialistas rechazaron dos proyectos de

11 El índice se construye sobre cuatro dimensiones: 1) normatividad; 2) la labor del Congreso; 3) el presupuesto y la gestión administrativa; y 4) la participación, atención ciudadana y la rendición de cuentas. 
ley liderados por dicho comité. El primero trataba de enmendar el error en el padrón electoral cometido por el Registro Civil. Cuando quedaban menos de diez días para las elecciones, el gobierno quiso solucionar el problema pero no llegó a consenso con los legisladores. Luego, el gobierno ingresó al Congreso un proyecto de reajuste al sector público que en su articulado sorpresivamente lo vinculaba con un alza en las pensiones básicas solidarias. La idea era mezclar el poco popular reajuste salarial de $3,2 \%$ a los funcionarios con la popular alza de $10 \%$ en la pensión de los chilenos de menos recursos. La idea fue desechada. El reajuste de 3,2\% fue aprobado el 16 de noviembre por ambas cámaras luego de que la Cámara de Diputados rechazara anteriormente el proyecto el 2 y 9 de noviembre. La aprobación final fue lograda tras mucho desgaste en las relaciones entre ambos poderes.

La poca coordinación entre el Ejecutivo y el Legislativo también fue una de las lecturas que sacaron los partidos oficialistas tras la debacle electoral de las municipales. Los presidentes y los secretarios generales de los siete partidos de la Nueva Mayoría se reunieron para analizar los resultados. Tras hacer una autocrítica por la mala negociación interpartidaria y el exceso de críticas al interior de la coalición, los liderazgos partidarios acordaron mejorar la coordinación con el Ejecutivo, particularmente en la gestión territorial, y limitar la agenda legislativa (Ahumada y von Baer 2016, 26 de octubre).

\section{POTENCIALES CONSECUENCIAS DE LA DESLEGITIMACIÓN DEL SISTEMA POLÍTICO}

\section{Transformación del sistema de partidos}

No existen democracias sin partidos. Los partidos son uno de los principales responsables del funcionamiento de las democracias representativas. Ellos generan proyectos de gobierno que representan a grupos de votantes y/o posiciones ideológicas, y con sus ideas integran a las nuevas generaciones de ciudadanos al sistema político. Los partidos son la principal fuente de puestos electivos y no electivos del Estado. Son los actores centrales en las elecciones y son responsables de proveer candidatos y proyectos sobre los cuales los ciudadanos se pronuncian con su voto. Como son organizaciones estables, permiten coordinar y monitorear la actividad política de quienes resultan electos. Quienes lideran los partidos son parte central de la élite política. Mal que mal, Aldrich (1995) define a los partidos como coaliciones institucionalizadas de élites que buscan capturar y usar puestos políticos.

¿Pero qué pasa cuando los ciudadanos no tienen preferencias ideológicas que los ayuden a identificarse con un partido, ni casi confíen en los partidos que promueven proyectos colectivos? Hay en esencia dos alternativas: o los partidos existentes pierden relevancia como articuladores de la competencia política y se 
produce una personalización de la actividad política, o surgen nuevos partidos para reequilibrar y realinear el sistema.

En el primer escenario, si cada vez importan menos los partidos para conseguir votos, más importancia adquieren los candidatos. Los partidos se vuelven meras organizaciones que seleccionan a candidatos que pueden atraer votantes, lo que permite que las características individuales de ellos definan al partido y no sea la ideología del partido la que guíe el proceso de selección de los candidatos. En extremo, un sistema de partidos crecientemente disfuncional puede colapsar. En su estudio sobre el sistema de partidos en Venezuela (19882000) y Perú (1985-1995), Dietz y Myers (2007) identifican tres condiciones que llevan a su colapso: 1) la presencia de una crisis sostenida en donde se cuestiona la habilidad de los partidos de gobernar en democracia; 2) valores extremos de poca o mucha institucionalización partidaria, y 3) el surgimiento de una figura anti-élites con el anhelo de autoridad personal. El sistema de partidos chileno está lejos de colapsar, pese a que tiene elementos en dos de las tres condiciones (está bajo una crisis de confianza y sus partidos son muy institucionalizados, pero por ahora no ha irrumpido un líder populista como una amenaza seria). Pero, de continuar el declive, el sistema lo resentirá y permitirá la emergencia de liderazgos personalistas.

El segundo escenario parece más probable. En la derecha, pero particularmente en la izquierda, han surgido movimientos y partidos que buscan aprovechar la desafección ciudadana con los partidos. A lo largo de 2016, 12 partidos y movimientos de izquierda negociaron la creación de una coalición llamada Frente Amplio, con el objetivo de competir conjuntamente en las presidenciales y legislativas de 2017, rivalizando directamente con el electorado tradicional de la Nueva Mayoría (Carreño y Núñez 2016, 14 de diciembre). En la derecha han surgido partidos como Amplitud, registrado en enero de 2016 y liderado por ex militantes RN, en particular la senadora Lily Pérez y los diputados Karla Rubilar, Pedro Browne y Joaquín Godoy (Álvarez 2016, 19 de enero). En julio de 2016 el partido decidió llevar candidato presidencial propio, disputándole votantes principalmente a RN pero también a la DC (Emol 2016, 9 de julio). El partido Evolución Política, creado en el 2012 por políticos afines a RN, decidió en cambio que su precandidato presidencial, el diputado Felipe Kast, compitiera en las primarias de Chile Vamos. Para resumir, la desafección ciudadana ha producido una proliferación de partidos y movimientos, particularmente en la izquierda, que buscan realinear las fuerzas en el sistema de partidos tradicional. Las elecciones de 2017 demostrarán hasta qué punto los nuevos actores logran penetrar un territorio copado hasta ahora solo por dos grandes coaliciones.

\section{Emergencia de movimientos o líderes populistas}

La personalización de la política como consecuencia de la deslegitimación del sistema político puede conducir a la emergencia de movimientos o líderes 
populistas. Como la atracción de votos se centra en la personalidad de los candidatos y en las ofertas que hagan, es fácil que los candidatos se tienten por un discurso populista.

El significado de "populismo" es controversial, por lo que vale la pena discutirlo. Mudde y Rovira Kaltwasser (2017: 6) definen populismo como "una ideología delgada que considera a la sociedad fundamentalmente separada en dos campos homogéneos y antagonistas, la 'gente pura' contra la 'élite corrupta,' y que argumenta que la política debería ser una expresión de la voluntad general de la gente" ${ }^{12}$ En esta definición hay tres componentes principales, la "gente", la "élite", y la "voluntad general". Precisamente, lo que caracteriza a los populistas es que atacan y acusan a una "élite" por los males que padece la "gente común", por lo general descrita como un grupo social, que es a la vez honesto y trabajador. Esos componentes han estado presentes en muchos líderes del continente americano, desde Juan Domingo Perón (Argentina) a Evo Morales (Bolivia) a Donald Trump (Estados Unidos).

Los líderes populistas tienen más posibilidades de ganar justamente cuando entre los votantes existe la creencia extendida de que una minoría ejerce una influencia excesiva en los asuntos públicos, lo cual es agravado si es percibida como corrupta e incompetente. Las encuestas presentadas al principio de este artículo dan cuenta de que el malestar social con la élite está presente en la opinión pública chilena, lo que abre una ventana de oportunidades al discurso populista.

\section{Erosión democrática}

La Encuesta Nacional UDP 2005-2015 revela que la masa crítica de personas que responden que "la democracia es preferible a cualquier otra forma de gobierno" es bastante limitada: $56.5 \%$ en $2010,65.5 \%$ en $2011,54.9 \%$ en 2013 y $51.5 \%$ en 2015. Es una mayoría pírrica, que perfectamente podría bajar si cambian las circunstancias. Estas cifras están alejadas de las estimaciones de Diamond (1999: 68-69), quien propone que para que exista un "apoyo público abrumador" a la democracia se necesita que al menos entre el 70\% y el 75\% de las personas la consideren el mejor sistema de gobierno y que no más de un 15\% prefiera otro.

Si casi la mitad de los ciudadanos no cree en la primacía de la democracia, entonces esta puede sufrir una regresión autoritaria sin esperar una reacción cívica (y las instituciones democráticas no bastan por sí solas para defender a una población indiferente tanto al régimen como a las ideas políticas). En un libro revelador, Booth y Seligson (2009) analizan ocho países latinoamericanos y documentan que mayores niveles de apoyo a la democracia se asocian a mayor resistencia a cambiar de régimen, a apoyar golpes de Estado durante 
crisis socioeconómicas y a tomar la justicia en propias manos. Bajos niveles de legitimidad, en cambio, aumentan la aceptación de normas no democráticas para resolver problemas.

\section{DISCUSIÓN}

El 2016 tuvo como eje central una deslegitimación creciente de la élite política, a tal punto que se rompieron récords. La presidenta recibióla mayor desaprobación desde el retorno de la democracia, las elecciones municipales registraron el mayor ausentismo electoral desde 1990 y las encuestas revelaron cifras sin precedentes en desconfianza en las principales instituciones y organizaciones políticas, así como una desafección muy alta respecto a ideas políticas.

El artículo argumentó que la crisis de legitimidad se vio agravada por dos razones coyunturales y tres subyacentes. Un factor coyuntural fueron los problemas de gestión por parte del gobierno, especialmente por la marcha de las reformas educacional, laboral, constitucional, y tributaria, pero también por problemas de coordinación dentro del Ejecutivo, entre los partidos de la Nueva Mayoría, y en las relaciones ejecutivo-legislativas. Otro factor fueron los escándalos de corrupción que afectaron a varios miembros de las élites política y económica. Aunque fueron menos relevantes que en 2015, los escándalos continuaron ahondando la visión negativa que la ciudadanía tiene de las élites. A estas causas se añaden tres factores subyacentes que profundizan la deslegitimidad del sistema: un bajísimo nivel de confianza interpersonal entre chilenos, la alta desideologización de la sociedad civil, y una baja rotación en las élites. Finalmente, los indicadores negativos se vieron reforzados por un magro crecimiento económico (1,6\% en 2016).

Pese a los indicadores negativos destacados, las acciones del gobierno en 2016 trascenderán a través de cambios institucionales importantes. Entre otras cosas, el gobierno anunció la creación de dos nuevos ministerios, Bachelet promulgó la reforma laboral, y el Ejecutivo lanzó propuestas transformadoras que tendrán impactos positivos para los trabajadores (con el aumento de la tasa de cotización de la renta desde un $10 \%$ a un $15 \%$ ) y para mejorar la representatividad de los votantes de regiones (con la elección directa los intendentes). Asimismo, el gobierno sentó las bases para enviar un proyecto de cambio constitucional al Congreso.

¿Qué tendencias se observarán en 2017? Hay razones para anticipar algunas continuidades. Como el desapego de la actividad política, la baja rotación de las élites y la baja confianza interpersonal son características que trascienden gobiernos, es poco probable que los chilenos experimenten un "reencantamiento" con la democracia y los miembros de la élite política en el corto plazo. Tampoco es probable que el gobierno vea subir mucho sus índices de apoyo, considerando que el declive ha sido persistente desde 2014 y se aceleró desde la irrupción del caso Caval en febrero de 2015. Lo medular de las 
interrogantes surgidas en 2016 se aclarará cuando se divulguen los resultados de las elecciones legislativas y presidenciales de noviembre y se conozca la reconfiguración de las fuerzas políticas en Chile. ¿Será un año donde la Nueva Mayoría y Chile Vamos seguirán poblando los puestos de elección popular o, por primera vez desde 1990, las coaliciones verán su hegemonía amenazada por nuevos partidos y liderazgos? ¿Triunfará un discurso populista, o las distintas visiones ideológicas continuarán delineando la narrativa electoral? ¿Seguirá en declive la legitimidad del sistema político, o veremos un giro en participación y en la confianza en las instituciones públicas, en los partidos políticos, en la marcha del país, y en el sistema de gobierno? El año que se avecina es aún una página en blanco.

\section{REFERENCIAS}

Ahumada, María José y Alex von Baer. 2016, 5 de enero. “Gobierno y Nueva Mayoría dan por superadas sus diferencias." El Mercurio. Recuperado de http://www.elmercurio.com/ blogs/2016/01/05/38304/Gobierno-y-Nueva-Mayoria-dan -por-superadas-sus-diferencias.aspx

Ahumada, María José y Alex von Baer. 2016, 20 de octubre. "Presidenta acepta renuncia de Blanco y opta por mantener a comité político en medio de crisis por error en padrón electoral." Economía y Negocios. Recuperado de http:/ / www.economiaynegocios.cl/ noticias / noticias.asp?id=300481

Ahumada, María José y Alex von Baer. 2016, 26 de octubre. “La Moneda anuncia ajustes de autoridades y Nueva Mayoría pide otro trato con el Ejecutivo." Economía y Negocios. Recuperado de http:/ / www.economiaynegocios.cl/noticias/noticias.asp?id=302528

Aldrich, John H. 1995. Why Parties? The Origin and Transformation of Political Parties in America. Chicago: University of Chicago Press.

Álvarez, María Elena. 2016, 19 de enero. "Bachelet finalizaría su gobierno sumando cuatro nuevos ministerios." La Tercera. Recuperado de http://www.latercera.com/noticia/ bachelet finalizaria-su-gobierno-sumando-cuatro-nuevos-ministerios /

Álvarez, María Elena. 2016, 22 de noviembre. "Bachelet firma 12 acuerdos con Presidente de China en La Moneda." La Tercera. Recuperado de http://www.latercera.com/noticia/bachelet-firma-12-acuerdos-presidente-china-la moneda /

Álvarez, R. 2016, 19 de enero. "Amplitud entrega firmas al Servel y se convierte en partido político." La Tercera. Recuperado de http://www.latercera.com/noticia/amplitud-entrega -firmas-al-servel-y-se-convierte-en-partido-politico/

Álvarez, M.E. y C. Carreño, 2016, 13 de octubre. "Bachelet reprocha en público a sus ministros y pide no intervenir en debate presidencial." La Tercera. Recuperado de https: / / www.pressreader.com/chile/la-tercera/20161015/281659664563687

Arana, Ignacio. 2016. “¿Cómo evaluar a los integrantes de la élite política? Una propuesta basada en los presidentes americanos." Política 54(1): 219-254.

Banco Central de Chile. 2017. “Cuentas Nacionales. Evolución de la actividad económica en el año 2016". Santiago, Chile.

BID [Banco Interamericano de Desarrollo]. 2006. “The Politics of Policies, Economic and Social Progress in Latin America." Washington: Inter-American Development Bank.

BBC. 2016, 6 de junio. "Chile demanda a Bolivia en La Haya por el acceso al disputado río Silala." Recuperado de http:/ /www.bbc.com/mundo/america_latina/2016/06/160606_ america_latina_chile_boliv ia_demanda_haya_silala_dgm

Booth, John A. y Mitchell A. Seligson. 2009. The Legitimacy Puzzle in Latin America: Political Support and Democracy in Eight Nations. Cambridge University Press. 
Bourlier, Amanda. 2016, 25 de abril. “Lo que le espera a Falabella en México tras su joint venture con Soriana." América economía. Recuperado de http:/ / www.americaeconomia.com/ analisis-opinion/lo-que-le-espera-falabella-en-mexico -tras-su-joint-venture-con-soriana

Burgos, Gabriela. 2016, 29 de agosto. "Chile: Copec compra cadena de estaciones de servicio en EE.UU. por US\$535 millones." Recuperado de http://www.america-retail.com/ chile/chile -copec-compra-cadena-de-estaciones-de-servicio-en-ee-uu-por-us535-millones/

Cádiz, Pablo. 2016, 8 de junio. "La historia de desencuentros entre Bachelet y el saliente ministro Jorge Burgos." T13. Recuperado de http:/ /www.t13.cl/noticia/politica/la -historia-desencuentros-bachelet-y-saliente-ministro-jorge-burgos

Castiglioni, Rossana. 2014. "Chile: elecciones, conflictos e incertidumbre." Revista de Ciencia Política 34(1): 79-104.

Cámara de Diputados. (2014-2016). Boletín Estadístico [varios años]. Valparaíso: Cámara de Diputados, Oficina de Informaciones Sección Estadística.

Campos, Paula y Abril Becerra. 2016, 23 de octubre. "Abstención alcanza récord histórico: Solo un tercio del electorado votó." Diario Uchile. Recuperado de http:/ / radio.uchile. cl/2016/10/23/abstencion-alcanza-record-historico-solo-un-tercio-del electorado-voto/

Canales, Paula y Camilo Fernández. 2016, 22 de febrero. "Bachelet pide disciplina a sus ministros y más trabajo en equipo." La Tercera. Recuperado de http:/ /impresa.lasegunda. com/2016/02/22/A/K02SK1HM/962SLB3T

Carreño, C y M. J. Núñez. 2016, 14 de diciembre. "Frente Amplio: 12 partidos de izquierda se reúnen hoy." La Tercera. Recuperado de http:/ / www.latercera.com/noticia/frente-amplio 12-partidos-izquierda-se-reunen-hoy/

Centro de Estudios Públicos. 2017. Encuesta CEP. Estudio Nacional de Opinión Pública $N^{\circ}$ 78 Recuperado de: https://www.cepchile.cl/estudio-nacional-de-opinion-publica noviembre-diciembre-2016/cep/2017-01-05/083311.html

Diamond, Larry. 1999. Developing Democracy: Toward Consolidation. Baltimore: The Johns Hopkins University Press.

Dietz, Henry A. y David Myers. 2007. "From Thaw to Deluge: Party System Collapse in Venezuela and Peru." Latin American Politics and Society 49(2): 59-86.

DW. 2016, 27 de febrero. "Bachelet y Rousseff piden colaborar para salir de la crisis." Recuperado de http://www.dw.com/es/bachelet-y-rousseff-piden-colaborar-para-salir-de-la-crisis/a -19078751

ebusinesshoy. 2016, 28 de diciembre. "Liverpool se prepara para conquistar Latinoamérica en 2017." Recuperado de http://ebusinesshoy.com/liverpool-se-prepara-para-despegar -conquistar-latinoamerica-en-2017/

Economía y Negocios. 2016, 20 de abril. “Grupo Arcano, de Alberto Chang, captó 240 millones de dólares de mil clientes." Recuperado de http://www.economiaynegocios.cl/ noticias / noticias.asp?id $=244554$

Economía y Negocios 2016, 26 de junio. “'Vocación de Paz': ambicioso libro marca nueva estrategia comunicacional chilena." Recuperado de http:/ / www.economiaynegocios. $\mathrm{cl} /$ noticias $/$ noticias.asp?id=265884

Economía y Negocios. 2016, 2 de septiembre. "Confuturo concreta compra de Espacio Urbano y prevé invertir hasta US\$ 150 mills." Recuperado de http:/ / www.economiaynegocios.cl/noticias/noticias.asp?id=285799.

Economía y Negocios 2016, 21 de septiembre. "Enjoy aprueba aumento de capital para que ingrese Advent International." Recuperado de http://www.economiaynegocios.cl/ noticias $/$ noticias.asp? id $=291890$

Economía y Negocios. 2016, 13 de diciembre. “Expertos responsabilizan a la deficiente gestión del Gobierno y reformas por 'bajón económico.'” Recuperado en http:/ / www.economiaynegocios.cl $/$ noticias $/$ noticias.asp?id=317572 
El Comercio. 2016, 2 de febrero. "Chile y Turquía firmaron acuerdo de cooperación." Recuperdo de http://elcomercio.pe/mundo/actualidad/chile-turquia-firmaron-acuerdo-cooperacion -209701

El Mundo. 2016, 25 de octubre. "La derecha se impone en las elecciones municipales de Chile." Recuperado de http:/ /www.elmundo.es/internacional/2016/10/24/580d5066e5fdea68318b456c.html

Emol. 2016, 9 de julio. "Amplitud acuerda llevar un candidato presidencial propio a la primera vuelta." Recuperado de http://www.emol.com/noticias/Nacional/2016/07/09/811737/Amplitud-acuerda-llevar-un candidato-presidencial-propio-a-la-primera-vuelta.html

Emol. 2016, 10 de julio. "Gobierno interviene Gendarmería tras escándalo por pensiones y alzas de sueldos." Recuperado de http://www.emol.com/noticias/Nacional/2016/07/10/811765/Gobierno-interviene-Gendarmeria-tras-escandalo-por-pensiones-y-sueldos.html

Cadem. 2017. Plaza Pública Cadem: Estudio N 169. Recuperado de: http:/ / plazapublica.cl/ wp-content/uploads/Track-PP159-Ene-S4-VF.pdf

Fernández, Renata. 2016, 24 de marzo. "Bolivia anuncia demanda por aguas del Silala y Chile dice que 'no acepta amenazas'." El Pulso. Recuperado de http://www.pulso.cl/ actualidad -politica/bolivia-anuncia-demanda-por-aguas-del-silala-y-chile-dice-queno-acepta -amenazas /

Fiscalía Nacional Económica (FNI). 2016, 6 de enero. "FNE acusa a Cencosud, SMU y Walmart por colusión en el mercado de la carne de pollo fresca." Recuperado de http:/ / www.fne.gob.cl/2016/01/06/fne-acusa-a-cencosud-smu-y-walmart-por-colusion enel-mercado-de-la-carne-de-pollo-fresca /

Fuentes, V. y A von Baer. 2016, 14 de octubre. "Ministro del Interior pide disculpas por opinar sobre carrera presidencial oficialista." Economia y Negocios. Recuperado de http:/ / www.economiaynegocios.cl/noticias/noticias.asp?id=298560

Gamboa, Ricardo, y Carolina Segovia. 2016. “Chile 2015: Falla política, desconfianza y reforma." Revista de Ciencia Política 36(1): 123-144.

Gestión. 2016, 29 de noviembre. "PPK y Michelle Bachelet firman tres acuerdos para profundizar relación Perú-Chile." Recuperado de http://gestion.pe/politica/ppk-y-michelle-bachelet -firman-tres-acuerdos-profundizar-relacion-peru-chile-2175931

infobae. 2016, 16 de diciembre. "Mauricio Macri y Bachelet se reunieron en Olivos." Recuperado de http://www.infobae.com/politica/2016/12/16/mauricio-macri-y-bachelet-se-reunen-en -olivos /

La Tercera. 2016, 17 de octubre. "Gobiernos de Chile y Argentina anuncian entrada en vigencia de convenio para eliminar la doble tributación." Recuperado de http:/ / www. latercera.com/noticia/gobiernos-chile-argentina-anuncian-entrada-vigencia convenio-eliminar-la-doble-tributacion/LATAM. 2016, 12 de julio. "LATAM Airlines Group y Qatar Airways firman acuerdo." Recuperado de https://www.latam.com/es_us/ prensa/comunicados-de -prensa/LATAMyQatarfirmanacuerdo/

López, Hernán y Francisco Artaza. 2016. "Las cuentas de la DC." La Tercera. Recuperado de http:/ / www.latercera.com/noticia/las-cuentas-de-la-dc/

Marchetti, Patricia. 2016, 29 de agosto. "Promulgan la reforma laboral: ¿Cuáles fueron las principales modificaciones?" Emol. Recuperado de http:/ / www.emol.com/noticias / Economia/2016/08/29/819506/Cuales-son-las-principales modificaciones-de-la-Reforma-Laboral.html

Marín, Verónica. 2016, 27 de octubre. “Tensión en el oficialismo: El 3-0 que los parlamentarios de la Nueva Mayoría le han marcado al Gobierno de Bachelet." Emol. Recuperado de http:/ / www.emol.com/noticias/Nacional/2016/10/27/828552/El-30-de-los parlame ntarios-de-la-Nueva-Mayoria-por-sobre-el-Gobierno-de-Bachelet.html

MORI. 2015. Estudio Nacional de Transparencia. Recuperado de: http:/ / www.consejotransparencia.cl/consejo/site/artic/20121213/asocfile/201212131554 1/estudio_nacional_de_ transparencia_2015.pdf 
Mudde, Cas y Cristobal Rovira Kaltwasser (eds). 2017. Populism: A Very Short Introduction. Oxford University Press.

Navia, Patricio. 2008. "Legislative Candidate Selection in Chile." En: P. Siavelis and S. Morgenstern (eds.) Pathways to Power: Political Recruitment and Candidate Selection in Latin America, University Park: Pennsylvania State University Press, 92-118.

Núñez, M. J. y M. F. Carrasco. 2016, 21 de marzo. "Dichos de Burgos por aborto complican al gobierno y abren críticas oficialistas." La Tercera. Recuperado de http://www.latercera.com/noticia/dichos-de-burgos-por-aborto-complican-al-gobierno-y -abren-criticas-oficialistas/

PNUD, 2016. "Mujeres y elecciones municipales de 2016." Recuperado de: http:/ / www.cl.undp.org/content/chile/es/home/library/democratic_governance/mujeres-y -elecciones-municipales-2016.html

Pulso. 2016, 14 de octubre. Caso Corpesca: Interponen querella contra ex ministro Pablo Longueira." Recuperado de http://www.pulso.cl/actualidad-politica/caso-corpesca interponen-querella-contra-ex-ministro-pablo-longueira /

Radio Cooperativa. 2016, 5 de enero. "Seis diputados recibieron préstamos de la Cámara sin intereses ni reajustes." Recuperado de https://www.cooperativa.cl/noticias/pais/politica/camara-de-diputados/seis-diputados -recibieron-prestamos-de-la-camara-sin-intereses-ni/2016-01-05/103753.html

Radio Cooperative. 2016, 21 de diciembre. "Caso SQM: La audiencia de revisión de cautelares de Pablo Longueira." Recuperado de https://www.cooperativa.cl/noticias/pais/ politica/caso sqm/caso-sqm-la-audiencia-de-revision-de-cautelares-de-pablo-longuei$\mathrm{ra} / 2016-12$ 21/160023.html

Red Latinoamericana por la Transparencia Legislativa. S.f. Índice de Transparencia Legislativa 2016. Recuperado de http:/ /indice.transparencialegislativa.org/

Repsol. 2016, 20 de abril. "Repsol acuerda con Abastible la venta de su negocio de GLP en Perú y Ecuador." Recuperado de https:/ /www.repsol.com/pe_es/corporacion/prensa/notas-de -prensa/ultimas-notas/04202016-repsol-acuerda-abastible-venta-glp-peru.aspx

Reuters. 2016, 23 de junio. "Chilean politician put under house arrest in wide corruption scandal." Recuperado de http://www.reuters.com/article/us-chile-crime-idUSKCN0Z91LO

Rodillo, Pablo. 2016, 9 de diciembre. "La relación Chile-Argentina al año de Macri." La Segunda. Recuperado de http:/ /impresa.lasegunda.com/2016/12/09/A/JP32BHTV/all

Rojas, Matías. 2016, 17 de junio. "La lista completa de oficiales de Gendarmería con pensiones ilegales, según Contraloría." El Ciudadano. Recuperado de http:/ / www.elciudadano. $\mathrm{cl} /$ chile/la-lista-completa-de-oficiales-de-gendarmeria-con pensiones-ilegales-seguncontraloria8356/06/17/

Segovia, Carolina, y Ricardo Gamboa. 2012. "Chile: El año en que salimos a la calle." Revista de Ciencia Política 32(1): 65-85.

T13. 2016, 1 de enero. "Este 1 de enero entró en vigencia el reajuste a la Pensión Básica Solidaria." Recuperado de http://www.t13.cl/noticia/nacional/te-puede-servir/este-1 enero-entro-vigencia-reajuste-pension-basica-solidaria

T13. 2016, 1 de febrero. "Bachelet promulga simplificación a la Reforma Tributaria y destaca avances en su Gobierno." Recuperado de http://www.t13.cl/noticia/politica/presidenta bachelet-promulga-simplificacion-reforma-tributaria

T13. 2015, 11 de marzo. "25 años de democracia: Los diputados y senadores que todavía están en el Congreso." Recuperado de http://www.t13.cl/noticia/actualidad/politica/25-anos-de -democracia-los-diputados-y-senadores-que-todavia-estan-en-el-congreso

T13. 2016, 22 de septiembre. “Quién es el desaparecido Rafael Garay?” Recuperado de http://www.t13.cl/noticia/negocios/quien-es-desaparecido-rafael-garay

T13. 2016, 20 de diciembre. "CMPC reconoce colusión con Kimberly Clark para subir precios de pañales." Recuperado de http://www.t13.cl/noticia/negocios/cmpc-reconoce-colusion -kimberly-clark-subir-precios-panales 
T13. 2016, 29 de diciembre. "Bachelet promulga ley que permite elección directa de intendentes." Recuperado de http://www.t13.cl/noticia/politica/bachelet-promulga-ley -permite-eleccion-directa-intendentes

Universidad Diego Portales. 2016. Encuesta Nacional UDP, 2005-2015. Recuperado de: http:/ /encuesta.udp.cl/descargas/tendencias/Encuesta\%20Nacional\%20UDP\%20 2005 2015.pdf

Vargas, Soledad. 2016, 13 de octubre. “Las claves para entender el error en el padrón electoral que afecta a casi 500 mil personas." 24 Horas. Recuperado de http:/ /www.24horas.cl/ municipales-2016/las-claves-para-entender-el-error-en-el-padron electoral-que-afectaa-casi-500-mil-personas-2160813

Vargas, Felipe y Benjamín Blanco. 2016, 18 de noviembre. "Bachelet vuelve a realizar un acotado cambio de gabinete: Paula Narváez será la nueva vocera y Krauss asume en Trabajo." Emol. Recuperado de http://www.emol.com/noticias/Nacional/2016/11/18/831758/Bachelet-concreta-el-sexto cambio-de-gabinete-de-su-Gobierno.html

Vargas, Felipe. 2016, 20 de noviembre. "Bachelet llama a líderes de APEC a consolidar un área de libre comercio entre todos los países de la región." Emol. Recuperado de http:/ / www.emol.com/noticias/Economia/2016/11/20/832055/Bachelet-llama-a-lideres deAPEC-a-consolidar-un-area-de-libre-comercio-entre-todos-los-paises-de-la region.html

Von Baer, Alex. 2016, 3 de junio. "Hollande: Chile es un ejemplo de democracia y estabilidad." Economía y Negocios. Recuperado de http://www.economiaynegocios.cl/noticias/ noticias.asp? $\mathrm{id}=258315$

Ignacio Arana Araya es doctor en Ciencia Política y actualmente realiza un postdoctorado en la Pontificia Universidad Católica de Chile. Puede ser contactado en iga3@pitt.edu y www. ignacioarana.com. 
- 